\title{
Sports Competitive Intelligence and its Influence on China Competitive Sports
}

\author{
Daliang Zhou*
}

School of P.E, Nanjing XiaoZhuang University, Nanjing 210000, Jiangsu, China

\begin{abstract}
As a kind of strategic resource, competitive intelligence is a kind of information activity of higher level. "Competitive intelligence" and "sports information" "sports competitive intelligence", it is a new understanding and awareness of the old "sports information" in the new period, which belongs to the "intelligence" and "competitive intelligence" the subordinate concept. In this paper, combining with the specific characteristics of sports and sports, the competitive intelligence and the core competence theory is extended to competitive sports field. In this paper based on lifting of competitive sports in China from the view of core competitiveness, using empirical research and case analysis, mathematical statistics and empirical research methods, in-depth and detailed discussions of sports competitive intelligence enhance the role of athletics sports of our country and implementation mechanism, build a sports competitive intelligence activity paradigm and enhance our country athletics sports competition performance model.
\end{abstract}

Keywords: Competitive sports, information, sports competitive intelligence.

\section{INTRODUCTION}

With its own unique physical characteristics of the industry and sports specific projects, from the enterprise competition intelligence theory research and practice achievements derived sports competitive intelligence and combining the competitive intelligence and competitive sports practice, mining the project winning rules in the sport of competitive intelligence characteristics, study of sports competitive intelligence how to cultivate and enhance the core competitiveness of weightlifting, gymnastics and other project process and the realization mechanism of the, the paper makes a summary of the sport of competitive intelligence is the project to build the best strategy for the core competitiveness (Fig. 1).

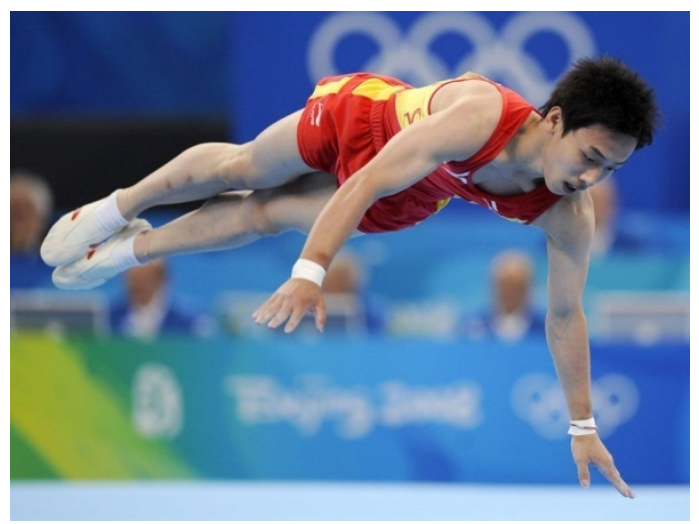

Fig. (1). Zou Kai in the 2008 Olympic Games in the gymnastics competition.

\section{SPORTS COMPETITIVE INTELLIGENCE}

\subsection{Competitive Intelligence}

The SCIP of the United States defined that: the competitive intelligence is a comprehensive monitoring process of the overall competitive environment. The earlier research well-known scholars in the competitive intelligence, competitive intelligence branch of the China Society for scientific and technical information, director emeritus of the Long Chang Mr. Huo Bao think, competitive intelligence is the information and research about the competitive environment, competitors and competitive strategy. It's both a process and a product [1]. Process, refers to the collection and analysis of competitive intelligence; product, then refers to the formation of information and strategy. This definition is in 1994 "national competitive intelligence and enterprise development seminar" the definition of competitive intelligence is "about the competitive environment, competitors and competitive strategy intelligence research" on the basis of further sublimation and confirmed.

\subsection{Sports Competitive Intelligence Analysis}

The sports competition within the same should be consistent with the core meaning of modern competition theory. The essence of competitive sports has come to the point of the first solution to the question of why competitions. Since sports competitive intelligence runs through in the whole process of the athletics competition logic, the next, the intelligence activities of sports competition is must resolve competes with whom (who), where competition (where), what the competition (what), how competition (how) "3W+1H" problem [2].

One is competes with whom (who) is to solve the competition subject, it mainly emphasizes who are the competitors, 
including the number and types of competitors, the differences of the competition between the behavior of the subject itself determines the size of its competition ability.

Two is where the competition (Where) is to solve the problem of time and space, that is, the environment and scope of competition.

Three what is the competition (What) and how to solve the problem of the object of the competition (How), that is, the purpose, the way and the strategy, which is the ultimate goal of the competition. In the fully weigh their own and competitor competitiveness based on, clear their goal of the competition determined they can in what aspects, in which sports have the strength to participate in the competition, should take what kind of methods try to maximize the interests of.

\subsection{Sports Competitive Intelligence Elements}

One is the competitor analysis: competition is a kind of social activity that the main body of a lot of competition. Competitors and competitors are the main body of the competition, but there are still some differences in the concept. The competitor is referred to all the behavior of the main competition on the field from its overall interests of the macro and micro levels, which in addition to all competitors outside themselves as competitors And competitors are from the micro level analysis of the competition, in the competitive field have the strength to compete with themselves or better than their competitors. Therefore, competitors are only a small part of the competitors, those who can pose a threat to their competitors can be called as competitors. The core problem that the competitive intelligence activity must solve is to determine the main competitors [3].

Two is the competitive environment analysis: the competition environment is the competition main body to participate in the competition the space and the place. The competitive environment, which is based on the sports teams, is the sum of the internal and external environmental factors that affect the sports team training and competition. The competitive environment analysis is the first step of the research on the competition strategy of the project team, and one of the main contents of the sports competition.

Competitive strategy analysis mainly includes judging and evaluating the competitor's current strategy and the goal of the competition is what, and our goal of the competition between, future competitors may make the competitive reaction, will bring to us? What are the effects, and the party should take action and competition strategy. Competitive strategy analysis and competition are closely related to one hand analysis and competitive environment analysis. The three constitute the framework of sports competitive intelligence analysis.

\subsection{Sports Competitive Intelligence Framework}

From the point of view of sports competitive intelligence research process, including sports competitive intelligence collection, sorting, processing, analysis, and service sectors; from the point of view of the analysis of elements of sports competitive intelligence, including competitor analysis, competitive environment analysis and competitive strategy analysis of three parts, the two parts constitute the twodimensional structure of sports competitive intelligence. Sports competitive intelligence analysis framework and main steps are as follows (Fig. 2):

(1) Judge and identify the main competitor;

(2) Competitive environment scanning, discovery of potential competitors;

(3) Understand the main competitor's target;

(4) Determine and confirm the main competitor's competitive strategy;

(5) Evaluate the strengths and weaknesses of the major competitors;

(6) Tracing the actions of competitors

(7) Determine the final party competition strategy.

\begin{tabular}{|c|c|}
\hline $\begin{array}{c}\text { Competitive environment } \\
\text { scanning, judging and identifying } \\
\text { major competitors }\end{array}$ & $\begin{array}{l}\text { According to the results of the } \\
\text { competition performance analysis, } \\
\text { identify the main competitors }\end{array}$ \\
\hline $\begin{array}{l}\text { Competitive environment } \\
\text { monitoring, discovery of potential } \\
\text { competitors }\end{array}$ & $\begin{array}{l}\text { Timely perception of changes in the } \\
\text { environment and potential } \\
\text { competitors may bring threats }\end{array}$ \\
\hline $\begin{array}{l}\text { To understand the main } \\
\text { competitors of the target }\end{array}$ & $\begin{array}{l}\text { Deep analysis of the strategic intent } \\
\text { of the main competitors }\end{array}$ \\
\hline $\begin{array}{c}\text { To judge and identifythe main } \\
\text { competitors' Competitive } \\
\text { Strategies } \\
\end{array}$ & $\begin{array}{l}\text { Master the current situation of the } \\
\text { major competitors }\end{array}$ \\
\hline $\begin{array}{c}\text { Evaluate the strengths and } \\
\text { weaknesses of your own and } \\
\text { major competitors }\end{array}$ & $\begin{array}{l}\text { Comprehensive competition between two or } \\
\text { more of the strengths and weaknesses, } \\
\text { profoundly understand the competitive } \\
\text { situation }\end{array}$ \\
\hline Track major competitors' actions & $\begin{array}{l}\text { In time to find the main competitors of the } \\
\text { strategic change, so that the party to make a } \\
\text { corresponding adjustment }\end{array}$ \\
\hline $\begin{array}{l}\text { Ultimately determine the } \\
\text { competitive strategy }\end{array}$ & $\begin{array}{l}\text { We should take which action to gain } \\
\text { competitive advantage. }\end{array}$ \\
\hline
\end{tabular}

Fig. (2). Schematic diagram of competitive intelligence analysis frame.

The main competitors are our focus on the object. But in sports practice, we should not ignore some potential competitors, sometimes potential competitors may be more threatening. Many outstanding athletes in major events were eventually defeated by some of the new, rather than the current major competitors are more examples.

\section{SPORTS COMPETITIVE INTELLIGENCE ACCESS PATH}

Data, information and knowledge are the basis of competitive intelligence. Need sports competitive intelligence personnel must leave no stone unturned to get some strong correlation information, and the weak relevance information acquisition process can be found hidden in these unclear information between the necessity to detect the very interesting relationship [4].

3.1. Understanding of Sports Competition and Information Knowledge by National and Provincial Sports Team Coaches

According to the content of sports competitive intelligence, function, usage and application point of view, you can 


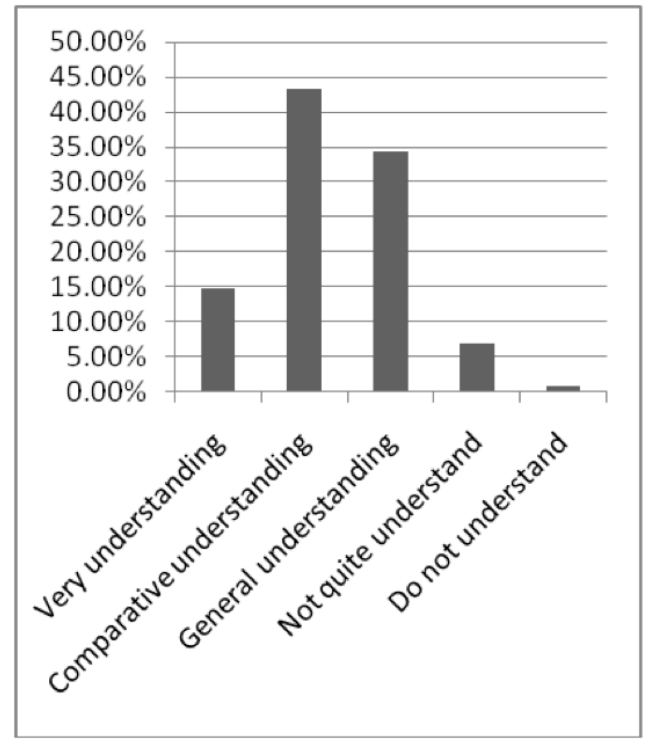

Fig. (3). The coaches to understand the competitive intelligence of sports.

divide it into three types: Strategic sports competitive intelligence and tactical sports competitive intelligence and technology sports competitive intelligence [5]. Strategic sports competitive intelligence is from the long-term, overall, comprehensive consideration, tries to solve fundamental, direction and overall problem with sports practice, tactics of sports competitive intelligence is considered in order to obtain a (sub) game stage victory, the force diagram to solve local or tactics of some specific problems; technical sports competitive intelligence is from improved consider sports teams (staff) the technical aspects of the sport, trying to solve some actual problems of sports teams (member) motion technology links.

Form Fig. (3), we can find that 102 weightlifting, gymnastics, badminton national team and Hunan, Shanghai and other provinces and cities sports team coaches, $57.9 \%$ of the coaches understand or know sports competitive intelligence related knowledge, $34.3 \%$ of the coaches answer, only $7.8 \%$ of the coaches don't know or don't know.

\subsection{Approaches and Methods of the National and Pro- vincial Sports Team Coaches to Obtain Competitive In- telligence}

Using an Internet search engine retrieval and access to related sites; the use of radio, television, newspapers and other print media; peer experts face to face communication; to participate in various domestic and international conferences and professional training; use sports system database; interpersonal network query; entrust related research and development personnel collected; panel; query literature of science and technology; by telephone, mail or email and other 10 kinds of Sports Competitive Intelligence Acquisition Ways and methods are coaches in different degree, used, mean scores between 3.0-4.0 (See Table 1). Even if the product is competitive intelligence software, although the average use of coaches and the lowest level of the average score only 2.83 , is $30.4 \%$ of the coaches said themselves more or pretty much use this kind of method [6].

Table 1. The way and method for the coaches to obtain competitive intelligence.

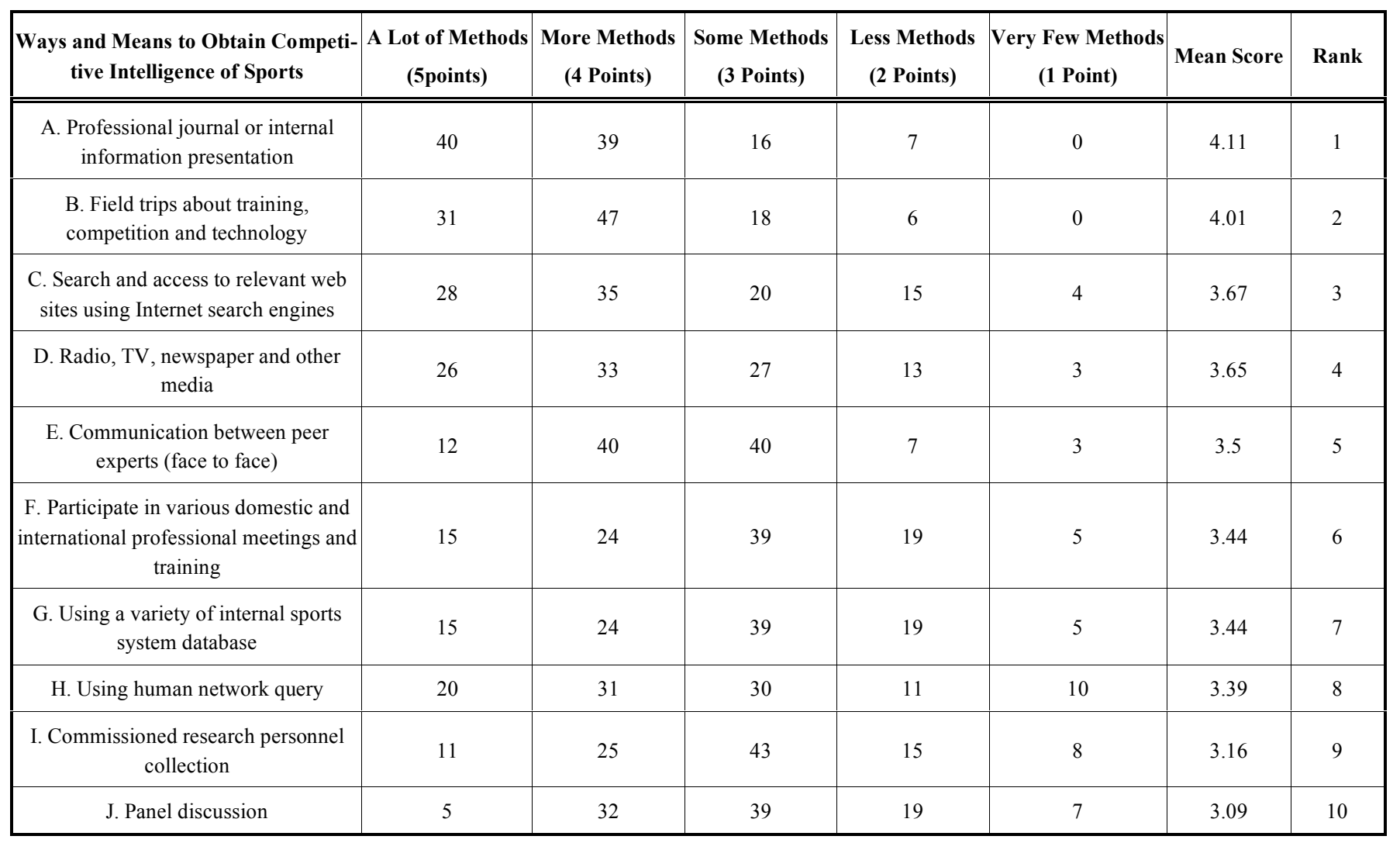




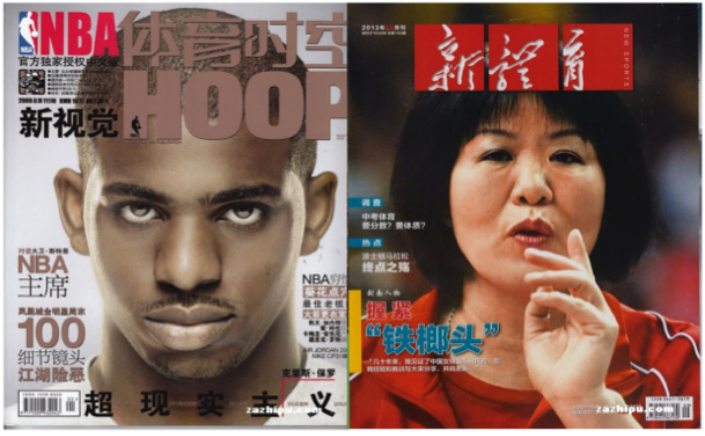

Fig. (4). Figure for the domestic sports professional publications.

Professional magazines or sports team internal information briefing, training and competition and the technical observation and other fieldwork is coaches get sports competitive intelligence the main ways and methods, the mean scores for 4.11 and 4.01 , the breakdown of the first and second place (Fig. 4).

\subsection{Sports Team in the Daily Sports Training Competi- tion in the Competitive Intelligence Type}

The national team and the provincial and municipal sports teams need to compete in the daily training needs of a variety of sports competitive intelligence.

In addition to the new training methods, means and intelligence; competitive rivals dynamic information; new scientific and technical information; competitive strategic intelligence and other four kinds of most in need of sports competitive intelligence type, unique because each event group classification and performance evaluation method is not the same, and the sports law of winning, in a certain extent, will affect the various sports teams sports competitive intelligence of the content, nature and trend.

Statistical results in Table 2 show that the new training methods, means and intelligence; competitive rivals dynamic information; new scientific and technical information; competitive strategic intelligence and other 4 kinds of intelligence type front, mean scores are above 4.0, belonging to the sports team most in need of everyday sports competitive intelligence types.
3.4. The Understanding on the Function of the Coaches on the Internet Communication of Sports Competition

Internet is the world's most open, the most public information dissemination channels, but also the most widely competitive intelligence sources. It is not only possible to retrieve relevant information in a timely manner, almost without any restrictions on the distribution and delivery of messages. You can also send e-mail, query audio and video data, the establishment of interpersonal network, etc. 121 as early as 1992, Rayjean on through the survey pointed out: a lot of business people in the family computer time consumption, there is a link between the $3 / 4$ and its professional activities. Retrieve the papers of the jointly sponsored by the State General Administration of sports gymnastics management center and sports information center from 1999 to 2008 118 "Gymnastics", there are a considerable number of the source on the Russian sports bulletins, agency of the new tower, American gymnast, international gymnastics, U.K. operation, the association's website, the Yomiuri Shimbun of Japan and Gymnastics Federation website foreign gymnastics power related websites and media published the translation and interpretation of the information, content involves foreign gymnastics power leadership people change, interviews and comments after the game, academic research, competition results announcements, sports team members adjust, new the difficult new technology action and so on [7].

Coaches of Internet dissemination of sports competitive intelligence characteristics not know tends to unity, on the timeliness and accuracy of Internet dissemination of sports competitive intelligence, two scores mean, although ranked in the top two, but no more than 4.0 (Table 3 ).

\section{SPORTS COMPETITIVE INTELLIGENCE IM- PLEMENTATION STRATEGY}

In December 2006, in order to meet the needs of the development of sports, to conform with international further, uniform standards, promoting the sports scientific, standardized management, the State Sports General Administration of China officially launched the sports project again reclassification adjustments. Adjustment after the official launch of our sports project a total of 78 , in addition to diving, body-

Table 2. Competitive intelligence type of sports required in the daily sports training competition.

\begin{tabular}{|c|c|c|c|c|c|}
\hline Sports Information Type Need by the Sport Teams & $\begin{array}{l}\text { Urgent Need } \\
\text { (5 Points) }\end{array}$ & $\begin{array}{c}\text { Need Some } \\
\text { (3 Points) }\end{array}$ & $\begin{array}{l}\text { No Need } \\
\text { (1 Point) }\end{array}$ & Need Degree & Rank \\
\hline A. New training methods, means and other information & 65 & 26 & 11 & 4.06 & 1 \\
\hline B. Competitive Intelligence & 54 & 47 & 1 & 4.04 & 2 \\
\hline C. New science and technology information & 54 & 45 & 3 & 4.00 & 3 \\
\hline D. Competitive strategy information & 57 & 39 & 6 & 4.00 & 4 \\
\hline E. Contest rule information & 53 & 37 & 12 & 3.80 & 5 \\
\hline F. Competitive environmental information & 35 & 63 & 4 & 3.61 & 6 \\
\hline G. Sports team management information & 34 & 62 & 6 & 3.55 & 7 \\
\hline H. Policy and regulatory information & 31 & 62 & 9 & 3.43 & 8 \\
\hline
\end{tabular}


Table 3. Investigation and statistics on the effectiveness of the internet communication of sports competitive intelligence.

\begin{tabular}{|c|c|c|c|c|c|c|c|}
\hline $\begin{array}{l}\text { The Utility of the Internet for } \\
\text { the Dissemination of Sports } \\
\text { Competitive Intelligence }\end{array}$ & $\begin{array}{c}\text { Completely } \\
\text { (5 Pionts) }\end{array}$ & $\begin{array}{l}\text { Most of the } \\
\text { Situation } \\
\text { (4 Pionts) }\end{array}$ & $\begin{array}{r}\text { Generally } \\
\text { (3 Pionts) }\end{array}$ & $\begin{array}{c}\text { Not in Most of } \\
\text { the Situation } \\
\text { (2 Pionts) }\end{array}$ & $\begin{array}{c}\text { Absolutely Not } \\
\text { (1 Piont) }\end{array}$ & Degree & Rank \\
\hline A. Timely & 23 & 43 & 32 & 4 & 0 & 3.83 & 1 \\
\hline B. Accuracy & 23 & 44 & 27 & 8 & 0 & 3.80 & 2 \\
\hline C. Efficiency & 23 & 37 & 37 & 5 & 0 & 3.70 & 3 \\
\hline D. Security & 21 & 28 & 44 & 9 & 0 & 3.60 & 4 \\
\hline E. Two-way communication & 22 & 33 & 29 & 16 & 2 & 3.56 & 5 \\
\hline
\end{tabular}

building exercises, bowling, billiards and 44 non-Olympic events outside, embrace include table tennis, diving, weightlifting, gymnastics, badminton, shooting our advantage project, including 29 Summer Olympic Games official event, and curling, ice hockey, biathlon, skating, skiing, etc [8]. five Winter Olympics will race categories. These 34 Olympic Games are composed of the main body of competitive sports in China.

In the current information explosion era, of bounded rationality constraints, any people, organizations, and institutions are hard to beat some of their lack of knowledge and professional level, it is impossible to complete exhaustive collection of all the information. Therefore, in sports competitions, analysis competitors and other sports competitive intelligence demand are generally in a sports team based, scientific research is concentrated in specific sports and athletes. The core competitiveness of China's competitive sports is the 34 games will official event of the individual core competitiveness, integration and, the core competitiveness of the project is the concrete manifestation of the core competitiveness of sports. Belong to our country athletics sports absolute advantage projects in weightlifting, gymnastics, badminton, their core competitiveness is the core competitiveness of competitive sports in China Construction of the main body, to enhance and extend the core competitiveness of competitive sports must be timely improvement and extension of the advantages of the project's core competitiveness. Therefore, with the advantages of the project teams as the basis, to carry out intelligence activities of sports competition, both in data acquisition analysis, information tracking, or in the value chain process management seems more pertinence and practicality.

\subsection{Build a Sports Team Based on The Sports Team, to Develop the Full Awareness of the Full Information Competition}

To carry out sports competitive intelligence research based on sports team, we must take the cross disciplinary and multi personnel to participate in the work mode of the compound team cooperation organization, which is decided by the following reasons.

Vice chairman of the Standing Committee of the National People's Congress, Han Qi de, chairman of the China Association for science and technology in 2009 China Association for the $\mathrm{H}$ annual meeting stressed: the key point of development of science and technology nowadays is cross fusion, in recent years in our country science and technology lag behind, to a large extent is because very few of the subject can't cross and cross [9]. And the sports competition information is the product of multi discipline cross fusion.

The traditional economics and the game theory think, people are completely rational. In this regard, a famous American psychologist, 1978 Nobel laureate Herbert Alexander Simon questioned this view is a ideal model, and the first to put forward a "complete rationality is not exist", namely the "limited rationality" theory [10]. He said: because people by their own knowledge and ability limitation and external constraints, so that their behavior in the majority of cases are not completely rational, therefore, the reason is the limited rationality between completely rational and irrational. Therefore, rational person is ranged from complete rationality and non rationality of "bounded rationality", he said. Limited reason may make people in the collection and analysis of information, and to a certain extent, the effective use of information.

Sports competitive intelligence research itself is a very huge workload. Although public information source is the main way to obtain competitive intelligence, it is not that anyone has the ability to dig out useful information from the public information. Sports Competitive Intelligence Acquisition Capability affected by whether has trained professional knowledge, ability, methods and skills, the understanding is extremely keen information consciousness, advanced search and analysis tools, and how to overcome the information overload, information scattered, false intelligence recognition effects [11].

\subsection{To Establish a Correct View of Sports Competition and Scientific Evaluation of the Performance Value of Competitive Intelligence}

Sports competitive intelligence is a kind of work idea and attitude. In the continuous development of the construction of the sports information today, the traditional sports intelligence, research ideas and methods, indulging in pure sports science and technology intelligence and sports information field, based on a, secondary literature that general review, commentary and the overview of to results in the form of intelligence research has been difficult to meet the sports team sports competitive intelligence demand [12]. 
In the hyper competitive environment, collect and analyze intelligence itself is in order to compete, to sports teams based sports competitive intelligence idea should be: must give the project sports team coaches, managers and team medical research personnel, medical personnel and other multi-level, polymorphous type, diversification, choice of sports competitive intelligence service, passive service into active site service. According to the major domestic and foreign education competition, through on-the-spot investigation, questionnaire survey team, interview method, in-depth understanding of sports team training and competition needs of sports competitive intelligence, to analyze the dynamic changes of competitors as the starting point, for the final product in a concise, brief, accurate, refined text or audiovisual information clearly the formation of technical demonstration, forecast, feasibility analysis and decision-making research report, and then pushed to the sports team in the hands of decision-makers, the maximum possible to provide decision makers in decision-making and reference, during the implementation, timely tracking specific strategic and tactical action effect, strengthen the information communication, in order to the feedback process in accordance with the change of internal and external environment in a timely manner correction or restructuring has information, and there will be a special database or database, the concentrated storage, protection of information security, to lay the foundation for a new round of sports competitive intelligence cycle [13].

\subsection{Strengthen the Academic Research of Competitive Intelligence in Sports, Expand the Number of Relevant Professional Research Team}

Theory is the basis of practice. At present, foreign information is a word corresponding to the Information, the word intelligence corresponds to the Intelligence, the two boundaries are clear, not conflict. And, Intelligence used to appear in the field of international politics and military affairs. And our intelligence and information in two words for a long time are common corresponds to the English information, which in a certain extent is also in order to facilitate the international exchange and cooperation, lest our intelligence researchers the visits abroad to communicate with each other, be mistaken for our personnel is a military spy or economic espionage. In fact, China's intelligence research has been carried out around the scientific and technological information, which is also the cause of the twentieth Century 90's information is replaced by information to replace the potential internal cause [14].

But with the end of the 20th century world military confrontation in the ease, foreign intelligence activities has the penetration into the field of enterprise technology, intelligence of the original implicit "espionage", has also been replaced by EsePionage the "intelligence" of proper nouns. The information we are now referring to, in fact, refers to the Intelligence. To change information replace information caused great confusion in concept and connotation, the use of the term, foreign language translation of, already have scholars pointed out: should dares to use Intelligence. in the foreign translation [15].

Any objective things are contradictory unity. In the practice of athletic sports, absolutely not only our party carry out intelligence activities of sports competition, competitors must also actively take kinds of measures to collect sports competitive intelligence and effect research on the core competitiveness of competitive sports in China to obtain our sports competitive intelligence and secrecy itself is also a sports competitive intelligence and essential feature.

Therefore, in the use of sports competitive intelligence to win the game at the same time, should not be ignored to prevent the various sports competition information is stolen by the other side of the Anti Sports Competitive Intelligence work. Not only sports team sports competitive intelligence team members to attach great importance to the daily sports competitive intelligence security prevention, should also educate athletes with sports information and sports competitive intelligence security prevention knowledge, strengthen sports teams in secrecy and information responsibility investigation system construction, strengthen the security measures, clearly the scope of confidentiality, according to the sensitivity of the information, decided what information is most in need of protection, what information does not need protection, enhance sports teams all members of the confidential information consciousness, prevent the core secrets in the foreign exchange (such as the convening of pre match press conference, the media meet, warm-up match, scientific, and cultural exchanges and other) when inadvertently leaked.

\section{CONCLUSION}

The core competitiveness of competitive sports is an objective and material existence. It is contained in the core competitiveness of the sports, and by the individual sports events of the core competitiveness of the integration and become. The core competitive power of competitive sports is the organic integration of many factors that can bring about sustainable competitive advantage to the competitive advantage [16]. It is not born, it is not static, with life cycle. In order to gain a long-term and sustainable competitive advantage, the true source of that competitors timely conversion of its existing competitive edge and competitive advantage as the core competitiveness, and continue to maintain and maintenance ability.

Sports competitive intelligence is both a process and a product. From the point of view of sports competitive intelligence research process, including sports competitive intelligence collection, sorting, processing, analysis, and service sectors; from the point of view of the analysis of elements of sports competitive intelligence, including competitor analysis, competitive environment analysis and competitive strategy analysis of three parts, the two parts constitute the twodimensional structure of sports competitive intelligence. The competitor analysis is the core mission of competitive intelligence activities of sports must be solved, competition and utility value is a prominent feature of sports competitive intelligence, which is the difference between two essential attribute of sports information. Sports competitive intelligence value chain is determined by the demand, data mining and information collection, information integration and processing, screening and depth of intelligence analysis, summary refining sports competitive intelligence products, sports, competitive intelligence assessment, intelligent decision, into in eight areas of specific strategic and tactical ac- 
tions constitute a will of original data and sports information final conversion for the sports competitive intelligence to provide quality information service network closed loop. In a sense, in the process of competitive intelligence value chain, people collect information and output information.

\section{CONFLICT OF INTEREST}

The author confirms that this article content has no conflict of interest.

\section{ACKNOWLEDGEMENTS}

Declared none.

\section{REFERENCES}

[1] C.K. Prahlad, and G. Hamel, "The core competence of the corporation", Harvard Business Review, vol. 68, no. 3, pp. 79-91, 1990.

[2] S. Hughes and R.J. White, "Competitive intelligence in higher education: opportunities and threats", Academy of Educational Leadership Journal, vol. 10, no. 2, pp. 67-81, 2006.

[3] F.M. Scherer, "Schumpeter and plausible capitalism", Journal of Economic Literature, vol. 30, pp. 1419-1423, 1992.

[4] K.J. Brow, "Theory and experiments on spatial competition", Economic Inqury, vol. 34, no. 1, pp. 139-142, 1993.
[5] A.D. Chandler, Strategy and Structure, Cambridge, MA: MITPress, 1962

[6] R.P. Rumelt, D. Schendel and D.J. Teece, "Strategic management and economics", Strategic Management Journal, vol. 12, pp. 5-29, 1991.

[7] M.E. Porter, Competitive Advantage. New York: The Free Press, 1985.

[8] M.E. Porter, Competitive Strategy, New York: The Free Press, 1980.

[9] W.R. Sandberg, "Strategic management's Potential contributions to a theory of entrepreneurship", Entrepreneurship Theory and Practice, vol. 16, no. 3, pp. 73-90, 1992.

[10] M. Gross, “Competitive intelligence: librarian's empirical approach", Seareher, vol. 8, no. 8, 2000.

[11] R.A. D'Aveni, Hyper-Competition Rivalries-Competing in Highly Dynamic Environments, New York: The Free Press, 1995, pp. 1-4.

[12] R.L. Cantrell, "The six angles of competition", Competitive Intelligence Review, vol. 10, no. 3, pp. 51-57, 1999.

[13] D.C. Hambriek, "Specialization of environmental seanning activities among upper Ievel executives", Journal of Management Studies, vol. 18, pp. 299-320, 1981.

[14] E.D. Thompson and M.L. Kaarst-Brown, "Sensitive information: a review and research agenda", Journal of American Society for Information Science and Technology, vol. 56, no. 3, pp. 245-257, 2005.

[15] H.A. Simon, Models of a Man: Essays in Memory of Herbert A. Simon, Cambridge, Mass, The MIT Press, 2004

[16] T.F. Krol, "Scientific competitive intelligence in R\&D decision making, USA”, Drug Information Journal, vol. 30, pp. 243-255, 1996.

(C) Daliang Zhou; Licensee Bentham Open.

This is an open access article licensed under the terms of the (https://creativecommons.org/licenses/by/4.0/legalcode), which permits unrestricted, noncommercial use, distribution and reproduction in any medium, provided the work is properly cited. 